\title{
REFLECTION
}

\section{Caring for a Surge of Hurricane Katrina Evacuees in Primary Care Clinics}

Thomas D. Edwards, DO

Richard A. Young, $M D^{1}$

Adonna F. Lowe, RN $N^{2}$

1JPS Family Medicine Residency Program, JPS Health Network, Fort Worth, Tex

${ }^{2}$ JPS Health Network, Fort Worth, Tex
Conflicts of interest: none reported

\section{CORRESPONDING AUTHOR}

Thomas Edwards, DO JPS Family Medicine Residency Program JPS Health Network 1500 S Main

Fort Worth, TX 76104

tanukidoc@comcast.net

\begin{abstract}
Primary care physicians are rarely mentioned in medical disaster plans. We describe how a group of mostly family physicians and administrators of the JPS Health Network (JPS) took primary responsibility for 3,700 evacuees of Hurricane Katrina who came to Tarrant County, Texas. JPS provided medical care to $1,664(45 \%)$ evacuees during a 2 -week period. The most common needs were medications for chronic illnesses and treatment of skin infections (primarily on the feet). The JPS Emergency Department saw only 148 evacuees, most of whom arrived by their own transportation and were not seriously ill. JPS created a triage center located several miles from the hospital that referred almost all evacuees with health care needs to a primary care clinic. It was an effective approach for caring for the medical needs of disaster victims and prevented an emergency department and hospital from being overwhelmed. The JPS experience may guide future planning efforts for natural or manmade disasters, especially pandemic threats.
\end{abstract}

Ann Fam Med 2007;5:170-174. DOI: 10.1370/afm.646.

\section{INTRODUCTION}

II T've lost everything," a former New Orleans resident quietly muttered, as she held on to a trash bag that contained all of her salvageable

possessions. As caregivers of Hurricane Katrina evacuees, we cannot count how often we heard that story. Despite the heavy emotional burden borne by the evacuees, their resolve to get through the immediate disaster and rebuild their lives was inspiring. We were privileged to be able to listen to their stories and help them recover, and we would like to share an important aspect of that experience.

We describe how the JPS Health Network (JPS) managed the medical needs of many of the evacuees of Hurricane Katrina who came to Fort Worth, Tex, and how the network kept evacuees out of its Emergency Department (for the most part). JPS is the integrated tax-supported county health care system for Tarrant County, Tex, and sponsors the nation's largest family medicine residency program. Additional resources include 27 community health centers and 10 pharmacies.

\section{BACKGROUND}

JPS was forced to deal with the issue of surge capacity, which is the ability to manage a sudden, unexpected increase in patient volume that would otherwise severely challenge or exceed the current capacity of the health care system. ${ }^{1}$ The management of surge capacity has been discussed for emergency departments, ${ }_{1}^{1-3}$ larger hospitals, ${ }_{1}^{4-11}$ and communities. ${ }^{1}$ Some have suggested using nontraditional triage and treatment spaces, such as local convention centers, prepackaged trailers, state mental health and 
detention facilities, and hospital cafeterias. ${ }^{1,3}$ We found almost no literature on the role of family physicians in caring for disaster victims.

\section{SEQUENCE OF EVENTS \\ JPS Is Asked to Help}

Two days after the hurricane struck, the Federal Emergency Management Agency (FEMA) activated its emergency preparations plan in the 6 surrounding states to assist in the evacuation of Gulf Coast residents. JPS received the initial call from the Tarrant County Emergency Operations Command (EOC) that Wednesday evening, August 31, 2005, to begin preparations to receive evacuees. The Tarrant County EOC coordinated efforts with local emergency medical services, police and fire departments, public health departments, the Red Cross, local military resources, and local city and county administrations.

\section{Evacuees Begin Arriving}

The first 250 evacuees arrived in Forth Worth by C130 transport planes in the early morning of Thursday, September 1. Most of these evacuees had been at the Superdome in the early days of the flooding and were transported to a nearby airport. Evacuees with the most severe medical problems were put on planes; the others were put on buses. Initially, this group of evacuees was slated to go Houston, but they were rerouted to the Fort Worth-Dallas area. A center in Mesquite, Tex, a suburb of Dallas, directed subsequent evacuee distribution across the region. Some evacuees spent more than 16 hours on a bus.

Critically ill evacuees were transferred directly to local hospitals, while those who were not critically ill were housed in a shelter established at a Fort Worth community center. Two hospitalized patients were transferred directly from the Gulf Coast area. That evening, another 200 evacuees arrived by bus, and a second shelter was established. The next morning, 250 more evacuees arrived and a third shelter was set up.

\section{From Hundreds to Thousands}

By Friday, September 2, the Tarrant County EOC and JPS recognized that several thousand more evacuees would arrive and that a location was needed where all evacuees could be medically triaged and assigned to shelters. JPS recognized that its previous disaster plans did not fit this catastrophe. The network had plans to such handle emergencies as plane crashes or limited terrorist attacks - scenarios that would create perhaps 100 acutely ill or injured patients. It had no plan to care for the needs of thousands of disaster victims who were not critically ill.
JPS worked with other local agencies to establish a centralized receiving center at a sports complex of the Fort Worth Independent School District that was close to a JPS community health center. As the buses of evacuees arrived, a physician or nurse met each bus at the receiving center. Patients with immediate medical needs stayed on that bus and were taken to the clinic. Others were taken by a different bus to shelters located throughout the community. Very few patients came to the receiving center by private transportation. Approximately $40 \%$ of the air-lifted evacuees and $25 \%$ of the bussed evacuees requested immediate medical care upon arrival in Tarrant County.

Twenty-five separate shelters were eventually established throughout Tarrant County, each housing no more than a few hundred evacuees, for an estimated total of 4,500 evacuees who stayed in shelters. (We have no way of knowing how many evacuees stayed in private homes or hotels.) This dispersion probably allowed the Tarrant County evacuees to avoid some of the problems encountered by evacuees who stayed in large complexes in other cities, such as the threat of wide-spread diarrhea. ${ }^{12}$

The University of North Texas Health Science Center (UNTHSC) took responsibility for the medical needs of approximately 400 evacuees at 1 shelter. The Tarrant County Medical Society took responsibility for the medical needs of 400 other evacuees divided between 2 other shelters and also helped at the UNTHSC center. JPS took responsibility for the remaining 3,700 evacuees.

\section{Outpatient Care}

Approximately 900 patients were seen at JPS clinics during the first 5 days that preceded and included the Labor Day weekend. Most patients arrived on Friday, September 2, and Saturday, September 3 (Figure 1). On September 2 nd, patients were seen at 2 clinic sites. Additional physicians and other support personnel were brought in to handle the extra volume. Existing patient appointments were not seriously affected. On September 3, clinic operations were consolidated to 1 clinic that would normally be closed for the weekend.

The patients seen that first weekend had the most urgent needs. The most common request was for prescriptions for essential medications that were left behind, such as insulin. Of the acute illnesses, most were for skin infections (primarily the feet), followed by vaginitis and respiratory illnesses.

During the initial 5-day surge period, the health care team comprised 8 attending family physicians, 1 attending psychiatrist, and approximately 15 family medicine residents. Time commitments ranged from a few hours to all day; physicians came and left as their 
other duties allowed. Other members of the team included 33 administrative staff, 55 nurses, 9 mental health professionals, 36 pharmacists and related staff, 57 clerical staff, 26 police and transportation staff, and 35 community volunteers.

The JPS administration asked the Family Medicine Department to spearhead the medical relief efforts. Although other departments were willing to help, the Family Medicine Department had the capacity to meet the medical needs of the evacuees and did not request additional physicians. The clinic stayed open each day until the last busload of patients had arrived. On the busiest 2 days, clinic hours were approximately 8:00 AM to 10:00 PM.

JPS clinicians treated the evacuees throughout our community clinic system after that first weekend. The clinics were staffed mostly by family physicians, but staff also included internists, pediatricians, obstetrician/gynecologists, and midlevel clinicians. The evacuees were scheduled between visits for patients who already had appointments. Transportation was arranged by JPS to take patients from the community shelters to the nearest JPS clinic. Each clinic stayed open later than usual to handle the increased patient load. There was a decrease in the number of patient visits on September 10 and 11, because most clinics were closed that weekend (Figure 1).

\section{Inpatient and Emergency Department Care}

JPS admitted 40 patients (2.4\% of 1,664 who sought medical care from JPS; $1.1 \%$ of the total JPS evacuee population) from September 1 through 14, most often after an evaluation at a network clinic. The most common indication for admission was a cardiovascular complaint, including angina, heart failure, atrial fibrillation, and deep vein thrombosis (18\%), followed by psychiatric issues, primarily from patients with chronic psychiatric diagnoses who had run out of their medications (10\%). These patients were admitted to a variety of JPS inpatient services.

Of the 1,664 evacuees who sought medical care during the first 2 weeks of September, only 148 (9\%) sought care through the Emergency Department. Almost all the Emergency Department patients arrived in Tarrant County by their own transportation, were not processed through the receiving center, and were not seriously ill.
We transported medical supplies, including prescription medications, by shuttle buses from the main hospital campus. We gave evacuees pharmaceutical samples whenever possible. For chronic disease medications, prescriptions were taken to the onsite pharmacy immediately after the evacuees were examined by the physicians. Evacuees would return to that pharmacy the next half-day to receive their medications (morning prescription drop-offs would be ready by that afternoon; afternoon drop-offs would be ready by the next morning). The JPS administration committed to provide a 6 -month supply of all medications to the evacuees at no charge.

\section{LESSONS LEARNED}

JPS learned many valuable lessons that we hope will aid future disaster planning:

- The breadth of knowledge and skills that family physicians possess is an invaluable asset given the inherent uncertainties of a disaster. Non-family physicians in another city reported their discomfort caring for patients outside their specialty; the general chaos of the situation resulted in physician encounters with evacuees for whom they were not trained to care. ${ }^{13,14}$ Other physicians noted the difficulty in planning for patient arrivals, because buses said to contain children were actually full of adults. ${ }^{12}$

- An integrated health network that oversees the main hospital, clinics, and pharmacies is well equipped to handle the complexities of a major disaster. Available resources were coordinated to meet the needs of both clinicians and patients. For example, the JPS system had
Figure 1. Number of Katrina evacuees treated during the first 14 days of September, 2005.

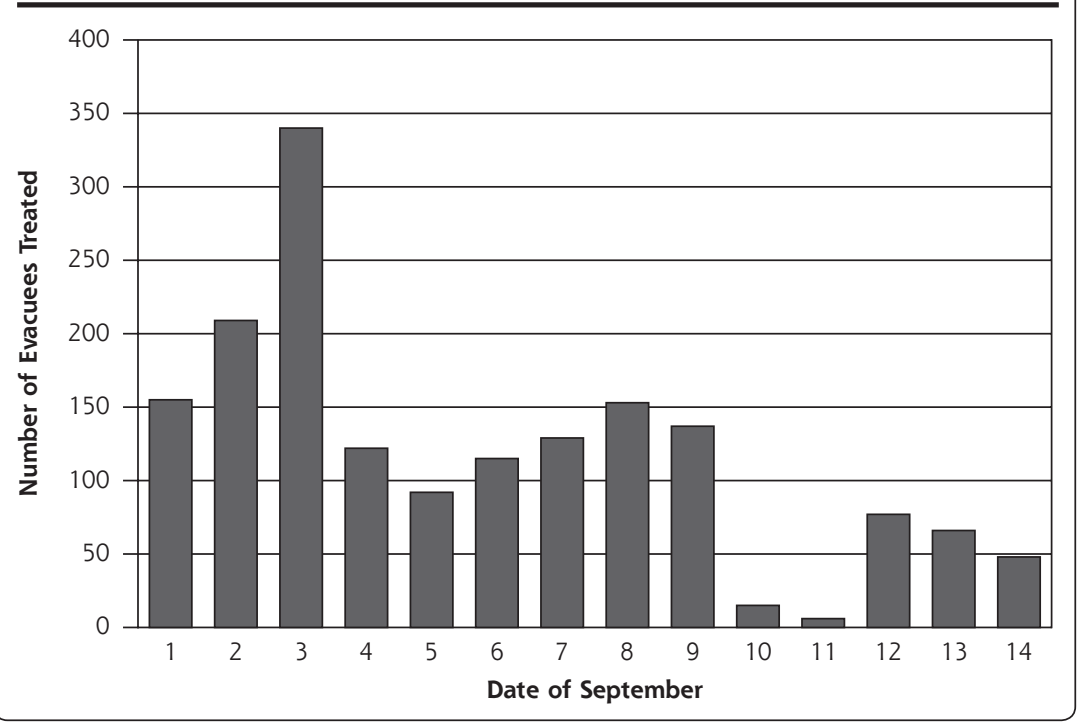


some transportation capacity (vans and shuttle buses) and was able to coordinate other transportation needs with local agencies. Pharmacy and communication resources were also readily available. Evacuees could have their prescriptions filled by the next half-day, and there were no medication shortages across the network

- Future disaster planners should not assume that most victims of a disaster require hospitalization or even emergency department evaluation. We recognize that the 560-mile distance between New Orleans and Fort Worth probably allowed JPS to care for a population that was less acutely ill than the population encountered by facilities closer to New Orleans; however, most survivors of other recent disasters had conditions that were not severe and did not require hospitalization (Table 1).2,5,15-18 This reality has been noted in previous commentaries on disaster planning. ${ }^{1,19}$

- The greatest medical need for displaced adult disaster victims is continuation of chronic disease care, not acute care. After 2 weeks, $44 \%$ of the evacuees eventually sought medical help, most often for chronic disease care. Many admissions were for exacerbations of chronic illnesses in evacuees who were unable to retrieve medications from their homes.

- To avoid overwhelming the emergency department and main hospital facilities, initial triage and treatment facilities should be established at a location removed from the emergency department. A family medicine clinic was an ideal place to treat the myriad needs of the evacuees. Examination facilities were in place (though many interviews occurred in nontraditional areas, such as the corners of meeting rooms), supplies to care for skin infections and lacerations were available, and small supplies of pharmaceutical samples were available to initiate immediate treatment.

- Immediate mental health efforts should focus on practicalities, such as finding lost relatives and assisting with immediate personal needs. Psychological debriefing immediately after trauma does not improve long-term outcomes and may actually be harmful. ${ }^{20-22}$ The psychiatrist who saw patients that first weekend primarily cared for evacuees with severe mental illness who had been off their medications. His expertise was invaluable in converting medications the evacuees had taken in Louisiana to those that were available on the JPS formulary.

\section{COMMENTS}

The JPS approach enabled care for a surge of undifferentiated patients with a wide variety of needs. This approach might be particularly useful in a future pandemic event, either from a naturally occurring threat such as severe acute respiratory syndrome (SARS) or

\begin{tabular}{|c|c|c|c|c|}
\hline Author & $\begin{array}{l}\text { Circumstance, } \\
\text { Location, and Year }\end{array}$ & Number of Casualties & $\begin{array}{l}\text { Number Taken } \\
\text { to the Hospital }\end{array}$ & Other Observations \\
\hline \multicolumn{5}{|l|}{ Manmade disasters } \\
\hline Cushman et al ${ }^{15}$ & $\begin{array}{l}\text { 9/11 attacks, New York } \\
\text { City, } 2001\end{array}$ & $\begin{array}{l}911 \text { casualties seen at } 2 \\
\text { hospitals located close } \\
\text { to ground zero }\end{array}$ & 911 & $\begin{array}{l}776(85 \%) \text { were "walking } \\
\text { wounded" } \\
135 \text { admitted with } 18 \text { under- } \\
\text { going surgery }\end{array}$ \\
\hline Ryan \& Montgomery ${ }^{16}$ & $\begin{array}{l}\text { Subway bombing in } \\
\text { London, } 2005\end{array}$ & $\begin{array}{l}\text { Location 1: } 80 \text { casualties } \\
\text { Location 2: } 100 \text { wounded } \\
\text { Location 3: No. wounded } \\
\text { N/A }\end{array}$ & $\begin{array}{l}38 \text { to hospital } \\
\text { Not reported } \\
236 \text { to hospital }\end{array}$ & $\begin{array}{l}24 \text { serious } \\
16 \text { severe } \\
36 \text { severe }\end{array}$ \\
\hline \multirow[t]{2}{*}{ Rodoplu et al ${ }^{5}$} & $\begin{array}{l}\text { Bombings at } 2 \text { different } \\
\text { buildings in Istanbul, } \\
2003\end{array}$ & 200 & 31 hospitalized (16\%) & $\begin{array}{l}171 \text { of } 184 \text { with lacerations } \\
\text { seen at } 1 \text { hospital }\end{array}$ \\
\hline & & Number Screened & $\begin{array}{l}\text { Number at } \\
\text { Increased Risk }\end{array}$ & Number Infected \\
\hline \multicolumn{5}{|l|}{ SARS threats } \\
\hline Tsai et $\mathrm{al}^{2}$ & $\begin{array}{l}\text { SARS outbreak at a } \\
\text { tertiary care hospital, } \\
\text { Taiwan, } 2003\end{array}$ & $\begin{array}{l}\text { 5,100 persons per day } \\
\text { underwent fever screen- } \\
\text { ing for } 23 \text { days }\end{array}$ & $\begin{array}{l}35 \text { per day }(<1 \%) \text { referred } \\
\text { for further evaluation } \\
382 \text { were fully evaluated }\end{array}$ & $\begin{array}{l}27 \text { were admitted } \\
3 \text { had SARS }\end{array}$ \\
\hline Svoboda et al ${ }^{17}$ & $\begin{array}{l}\text { SARS outbreak, } \\
\text { Toronto, } 2003\end{array}$ & $\begin{array}{l}316,615 \text { calls to SARS } \\
\text { hotline }\end{array}$ & $\begin{array}{l}23,103 \text { contacts of SARS } \\
\text { patients quarantined }\end{array}$ & $\begin{array}{l}2,132 \text { potential SARS cases } \\
225 \text { with SARS }\end{array}$ \\
\hline Pang et al ${ }^{18}$ & $\begin{array}{l}\text { SARS outbreak, Beijing, } \\
2003\end{array}$ & $\begin{array}{l}14 \text { million screened for } \\
\text { fever at the airport, } \\
\text { train stations, and road- } \\
\text { side checkpoints }\end{array}$ & $\begin{array}{l}30,178 \text { close contacts } \\
\text { quarantined }\end{array}$ & $\begin{array}{l}130 \text { probable SARS cases in } \\
\text { quarantined population } \\
12 \text { probable SARS cases } \\
\text { in general population } \\
\text { screening }\end{array}$ \\
\hline
\end{tabular}


a manmade threat such as a biological agent. Other commentators have noted gaps in pandemic planning $^{23}$ that the JPS experience might help fill. Previous SARS threats found that the number of concerned and exposed persons who sought treatment vastly outnumbered individuals who were infected with SARS (Table 1). Overcrowded emergency departments typically do not have the capacity to care for a surge of thousands. As for manmade threats, Wein et al determined that the primary bottleneck in treating the victims of an anthrax attack is caused by limited hospital capacity, and they estimated that the death rate from such an attack could be cut in half if this bottleneck were avoided. ${ }^{11}$ The JPS approach would eliminate that bottleneck.

If JPS had to do it all over again, not much would be changed. Perhaps next time there will be more effort to divert from the Emergency Department those patients who had concerns that were not severe (eg, the independent automobile visitors). One consistent theme we noticed in dozens of informal conversations with JPS personnel after the disaster is how smoothly the entire operation went. We hope that our experiences will help other locations care for large surges of disaster victims.

\section{To read or post commentaries in response to this article, see it} online at http://www.annfammed.org/cgi/content/full/5/2/170.

Key words: Natural disasters; relief work; emergency medicine; disaster planning; health planning

Submitted April 30, 2006; submitted, revised, September 7, 2006; accepted September 13, 2006.

A poster of these findings was accepted to be presented at the resident research poster exhibition of the AAFP Scientific Assembly, September 28-31, 2006, Washington, DC.

Acknowledgments: The authors thank David M. Cecero, CEO of the JPS Health Network, the JPS Board of Managers and administration, and Joane Baumer, MD, for their leadership during those extraordinary times. Anita Webb, PhD, provided helpful comments and suggestions in the preparation of this manuscript. We thank the members of the Tarrant County and Fort Worth Public Health departments and dozens of other volunteers who made this relief effort run as smoothly as it did.

\section{References}

1. Hick JL, Hanfling D, Burstein JL, et al. Health care facility and community strategies for patient care surge capacity. Ann Emerg Med. 2004;44(3):253-261.

2. Tsai MC, Arnold JL, Chuang CC, et al. Impact of an outbreak of severe acute respiratory syndrome on a hospital in Taiwan, ROC. Emerg Med J. 2004;21(3):311-316.

3. Space, staff key concerns in ED surge capacity plans. ED Manag. 2004;16(10):112-113.
4. Davis DP, Poste JC, Hicks T, et al. Hospital bed surge capacity in the event of a mass-casualty incident. Prehospital Disaster Med. 2005;20(3):169-176.

5. Rodoplu U, Arnold JL, Yucel T, et al. Impact of the terrorist bombings of the Hong Kong Shanghai Bank Corporation headquarters and the British Consulate on two hospitals in Istanbul, Turkey, in November 2003. J Trauma. 2005;59(1):195-201.

6. Hospitals' preparation for surge of patients helps with new Joint Commission standards. ED Manag. 2005;17(8):suppl 1-3.

7. Hoard M, Homer J, Manley W, et al. Systems modeling in support of evidence-based disaster planning for rural areas. Int J Hyg Environ Health. 2005;208(1-2):117-125.

8. Hirshberg A, Scott BG, Granchi T, et al. How does casualty load affect trauma care in urban bombing incidents? A quantitative analysis. J Trauma. 2005;58(4):686-693; discussion 694-685.

9. Higgins W, Wainright C, Lu N, Carrico R. Assessing hospital preparedness using an instrument based on the Mass Casualty Disaster Plan Checklist: results of a statewide survey. Am J Infect Control. 2004;32(6):327-332.

10. Braun BI, Darcy L, Divi C, Robertson J, Fishbeck J. Hospital bioterrorism preparedness linkages with the community: improvements over time. Am J Infect Control. 2004;32(6):317-326.

11. Wein LM, Craft DL, Kaplan EH. Emergency response to an anthrax attack. Proc Natl Acad Sci U S A. 2003;100(7):4346-4351.

12. Sirbaugh PE, Gurwitch KD, Macias CG, et al. Caring for evacuated children housed in the Astrodome: creation and implementation of a mobile pediatric emergency response team: regionalized caring for displaced children after a disaster. Pediatrics. 2006;117(5 pt 3):S428-438.

13. Thomas DE, Gordon ST, Melton JA, et al. Pediatricians' experiences 80 miles up the river: Baton Rouge pediatricians' experiences meeting the health needs of evacuated children. Pediatrics. 2006;117(1): S396-S401

14. Brown OW. Using international practice techniques in Texas: Hurricane Katrina experiences: receiving patients in Longview, Texas, 350 miles from ground zero. Pediatrics. 2006;117(6):S439-S441.

15. Cushman JG, Pachter HL, Beaton HL. Two New York City hospitals' surgical response to the September 11, 2001, terrorist attack in New York City. J Trauma. 2003;54(23):147-154; discussion 154-145.

16. Ryan J, Montgomery H. The London attacks--preparedness: Terrorism and the medical response. N Engl J Med. 2005;353(24):543-545.

17. Svoboda T, Henry B, Shulman L, et al. Public health measures to control the spread of the severe acute respiratory syndrome during the outbreak in Toronto. N Engl J Med. 2004;350(5):2352-2361.

18. Pang $X$, Zhu Z, Xu F, et al. Evaluation of control measures implemented in the severe acute respiratory syndrome outbreak in Beijing, 2003. JAMA. 2003;290(5 pt 3):3215-3221.

19. Kvetan V. Intensive care in a field hospital in an urban disaster area: are we ready? Crit Care Med. 2003;31(5 pt 3):1589-1590.

20. van Emmerik AA, Kamphuis JH, Hulsbosch AM, Emmelkamp PM. Single session debriefing after psychological trauma: a metaanalysis. Lancet. 2002;360(9335):766-771.

21. Rose S, Bisson J, Churchill R, Wessely S. Psychological debriefing for preventing post traumatic stress disorder (PTSD). Cochrane Database Syst Rev. 2002(2):CD000560.

22. Gray MJ, Maguen S, Litz BT. Acute psychological impact of disaster and large-scale trauma: limitations of traditional interventions and future practice recommendations. Prehospital Disaster Med. 2004;19(2):64-72.

23. Taylor JL, Roup BJ, Blythe D, et al. Pandemic influenza preparedness in Maryland: improving readiness through a tabletop exercise. Biosecur Bioterror. 2005;3(1):61-69. 